\title{
Caro leitor
}

A revista Texto Digital chega então a sua décima primeira edição. Dando continuidade ao trabalho dos editores anteriores, esta edição apresenta um dossiê especial que discute o cânone da literatura ocidental na era digital. Os artigos que compõem este dossiê foram apresentados no Workshop de pesquisa Western Canons in the Digital Era, realizado nos dias 31 de maio a 4 de junho de 2010 em Tel Aviv e organizado pela Tel Aviv University (The Lester and Sally Entin Faculty of Humanities e The Porter Institute for Poetics and Semiotics) e pela Israel Science Foundation.

A edição também traz dois artigos submetidos por seus autores. Iandra Pavanati, Richard Perassi Luiz de Sousa e Othon da Rocha Neves Jr. problematizam os conceitos de informação, conhecimento e representação na mídia eletrônico-digital. Daniel Ferreira e Gilberto Prado realizam uma introdução aos estudos de software (software studies) e investigam as ferramentas utilizadas nos processos de criação em meio digital.

Além do artigo, Gilberto Prado e Daniel Ferreira juntamente com todo o grupo Poéticas Digitais apresentam o processo de criação do projeto Amoreiras, realizado durante a Bienal de Arte e Tecnologia do Instituto Itaú Cultural entre os dias $1^{\circ}$ de julho a 5 de setembro de 2010 em São Paulo.

Boa leitura,

Tecia Vailati 